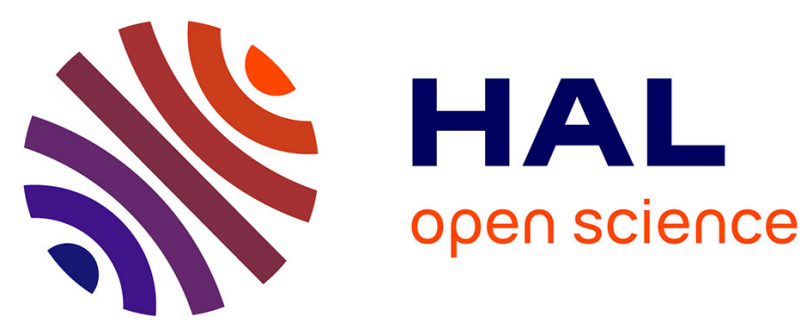

\title{
Distribution of mutation frequencies among isolates from animal and human sources and genetic characterization of a Heidelberg hypermutator
}

S. Le Gall, L. Desbordes, P. Gracieux, S. Saffroy, Latifa Bousarghin, M.

Bonnaure-Mallet, A. Jolivet-Gougeon

\section{To cite this version:}

S. Le Gall, L. Desbordes, P. Gracieux, S. Saffroy, Latifa Bousarghin, et al.. Distribution of mutation frequencies among isolates from animal and human sources and genetic characterization of a Heidelberg hypermutator. Veterinary Microbiology, 2009, 137 (3-4), pp.306. 10.1016/j.vetmic.2009.01.023 . hal00485535

\section{HAL Id: hal-00485535 \\ https://hal.science/hal-00485535}

Submitted on 21 May 2010

HAL is a multi-disciplinary open access archive for the deposit and dissemination of scientific research documents, whether they are published or not. The documents may come from teaching and research institutions in France or abroad, or from public or private research centers.
L'archive ouverte pluridisciplinaire HAL, est destinée au dépôt et à la diffusion de documents scientifiques de niveau recherche, publiés ou non, émanant des établissements d'enseignement et de recherche français ou étrangers, des laboratoires publics ou privés. 


\section{Accepted Manuscript}

Title: Distribution of mutation frequencies among Salmonella enterica isolates from animal and human sources and genetic characterization of a Salmonella Heidelberg hypermutator

Authors: S. Le Gall, L. Desbordes, P. Gracieux, S. Saffroy, L. Bousarghin, M. Bonnaure-Mallet, A. Jolivet-Gougeon

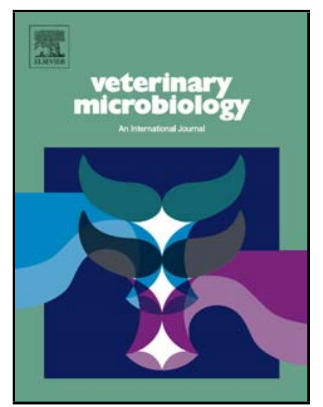

PII: S0378-1135(09)00043-1

DOI: doi:10.1016/j.vetmic.2009.01.023

Reference: VETMIC 4337

To appear in: $\quad$ VETMIC

Received date: $\quad$ 17-9-2008

Revised date: $\quad 8-1-2009$

Accepted date: $\quad$ 12-1-2009

Please cite this article as: Le Gall, S., Desbordes, L., Gracieux, P., Saffroy, S., Bousarghin, L., Bonnaure-Mallet, M., Jolivet-Gougeon, A., Distribution of mutation frequencies among Salmonella enterica isolates from animal and human sources and genetic characterization of a Salmonella Heidelberg hypermutator, Veterinary Microbiology (2008), doi:10.1016/j.vetmic.2009.01.023

This is a PDF file of an unedited manuscript that has been accepted for publication. As a service to our customers we are providing this early version of the manuscript. The manuscript will undergo copyediting, typesetting, and review of the resulting proof before it is published in its final form. Please note that during the production process errors may be discovered which could affect the content, and all legal disclaimers that apply to the journal pertain. 
Distribution of mutation frequencies among Salmonella enterica isolates from animal and human sources and genetic characterization of a Salmonella Heidelberg hypermutator

S. Le Gall ${ }^{\text {a }}$, L. Desbordes ${ }^{\text {a,b }}$, , P. Gracieux ${ }^{\text {a }, ~ S . ~ S a f f r o y ~}{ }^{\text {a }}$, L. Bousarghin ${ }^{\text {a }}$, M. BonnaureMallet ${ }^{\mathrm{a}, \mathrm{b}}$, and A. Jolivet-Gougeon* ${ }^{-\mathrm{a}, \mathrm{b}}$.

a Equipe Microbiologie, UPRES-EA 1254, Faculté des Sciences Pharmaceutiques et Biologiques, Université de Rennes 1, Université Européenne de Bretagne, 2 Avenue du Professeur Léon Bernard, 35043 Rennes, France

${ }^{b}$ CHU Pontchaillou, 2 rue Henri Le Guilloux, 35033 Rennes Cedex 9

* Corresponding author: Anne Jolivet-Gougeon, Equipe Microbiologie, UPRES-EA 1254, Faculté des Sciences Pharmaceutiques et Biologiques, Université de Rennes 1, 2 Avenue du Professeur Léon Bernard, 35043 RENNES, FRANCE.

Tel.: (33) $223234905 \quad$ Fax: (33) 223234913

Email: anne.gougeon@univ-rennes1.fr; anne.gougeon@chu-rennes.fr 


\begin{abstract}
Hypermutation is an important mechanism used by different Salmonella enterica subspecies enterica to regulate genetic stability in adaptation to changing environments, including antimicrobial treatments and industrial processes. Strong hypermutator strains generally contain a mutation in genes of the methyl mismatch repair (MMR) system and have mutation frequencies up to 1000 fold higher than wild type strains. The objectives of this study were to determine the distribution of mutation frequencies from a collection of 209 Salmonella strains, to genetically characterize a strong mutator, and to study MMR mutated protein-DNA binding interactions. Only one strain of $S$. Heidelberg was determined to have a hypermutator phenotype by virtue of its high mutation rate. Sequencing of genes of the MMR system showed a $12 \mathrm{bp}$ deletion in the $m u t \mathrm{~S}$ gene was present. The MMR mutated protein-DNA binding interactions were studied by bioanalysis, using the available crystal structure of a similar MutS protein from Escherichia coli. This analysis showed the small deletion in the Salmonella MutS was localized within the core domain. A retardation assay with MutS from hypermutable and wild type strains showed this mutation has no effect on MutS DNA binding. A better understanding of the genetic mechanisms of hypermutation will help to anticipate the behavior of hypermutator strains in various conditions.
\end{abstract}

Key words: Salmonella Heidelberg; MutS; hypermutation; DNA retardation assay; His6-tag protein. 


\section{Introduction}

Salmonella enterica subspecies enterica $(S$.) are transmissible from animals to humans (Vaillant et al., 2005) and many serovars, including S. Heidelberg, are responsible for foodrelated illnesses causing localized gastroenteritis, with increasing rates of resistance to multiple antimicrobial agents (Zhao et al., 2008). Hypermutable bacteria have an elevated mutation rate, up to 1000 fold higher than normal and the frequency of transduction can be 10-15 fold higher than normal (Leclerc et al 1996, Merino et al., 2002), compared to their wild-type counterparts (spontaneous mutator phenotype) (Matic et al., 1997). Hypermutable bacteria play a role in adapting to environmental stresses and thus, in developing antibiotic resistance (Taddei et al., 1997).

The majority of natural bacterial strains with the hypermutator phenotype harbor mutations in the methyl mismatch repair (MMR) system, predominantly in the mutS gene (Boe et al., 2000; Chopra et al., 2003; Matic et al., 2006). The essential role of this system is to correct errors that have escaped the proofreading function of polymerase, such as mismatches between base-pairs (bp) or errors due to insertions or deletions (Yang, 2000). This system relies on the activity of four major proteins: MutS, MutL, MutH, and UvrD. MutS proteins are responsible for repairing base mismatches and insertions and deletions up to four bases. MutS proteins also play a role in preventing recombination between nonidentical DNA sequences (Radman et al., 1995). In the presence of both ATP and a mismatch, MutS recruits MutL. Together they activate MutH and initiate the entire MMR system. Hypermutable strains have been detected in clinical settings among bacterial strains that colonized the lung of a cystic fibrosis patient (Oliver et al., 2000; Prunier et al., 2003) and the urinary tract (Denamur et al. 2002). 
The objectives of this study were (1) to determine the distribution of mutation frequencies from a collection of 209 Salmonella strains, of animal and human origin, to select a strain with a hypermutator phenotype by virtue of its high mutation rate; (2) to genetically characterize a strong mutator; and (3) to study MMR mutated protein-DNA binding interactions, using a gel shift assay and a 3D model of E. coli MutS protein.

\section{Material and methods}

\subsection{Bacterial strains and phenotypic identification}

A total of 209 Salmonella enterica strains were isolated from humans (62 clinical isolates from Rennes Hospital, France) and animals (112 cows, 25 pigs, 3 sheep, and 7 chickens, from the Veterinary Laboratory of Ille et Vilaine, France) from 1995 to 2005 (Table 1). Identification was performed with API (API 20E, API 32GN, BioMérieux, Marcy 1'Etoile, France). Escherichia coli M15 pREP 4 (Qiagen, Courtaboeuf, France) was used for cloning and constructing the His ${ }_{6}$-tagged plasmid, as described below.

\subsection{Mutation rates}

Mutation rates were determined as described previously (LeClerc et al., 1996). Briefly, a single colony was suspended in $10 \mathrm{~mL}$ of Luria Bertani (LB; AES Laboratory, Combourg, France) broth and incubated at $37^{\circ} \mathrm{C}$ for $24 \mathrm{~h}$. This pre-culture was inoculated at a dilution of 1:50 in $5 \mathrm{~mL}$ of fresh $\mathrm{LB}$ broth and then incubated at $37^{\circ} \mathrm{C}$ until $\mathrm{OD}_{600}=0.6$ was reached. One hundred microliters of culture were spread onto LB agar with or without rifampicin $(100 \mu \mathrm{g} / \mathrm{mL}$, Sigma Aldrich, Saint Quentin Fallavier, France). To confirm the mutator phenotype, the mutation frequencies that conferred resistance to the antibiotics nalidixic acid $(50 \mu \mathrm{g} / \mathrm{mL}$, Sigma Aldrich, Saint Quentin Fallavier, France) and fosfomycin $(100 \mu \mathrm{g} / \mathrm{mL}$, 
Sigma Aldrich, Saint Quentin Fallavier, France) were determined. Mutation frequencies are reported as a proportion of rifampicin-resistant colonies to the total viable count. The results were related to the mean value obtained from three independent cultures of $10^{8} \mathrm{CFU} / \mathrm{mL}$.

\subsection{Analysis of MMR gene sequences}

Bacterial DNA was extracted and purified using the Qiamp DNA mini kit (Qiagen, Courtaboeuf, France). The mut $\mathrm{S}$ (2568 bp), mut $\mathrm{H}$ (696 bp), mutL (1857 bp), uvrD (2163 bp), and dam (837 bp) genes were amplified by PCR (using primers shown in Table 2) with Phusion high-fidelity DNA polymerase (Finnzymes, Saint Quentin Yvelines, France) according to the manufacturer's recommendations. Amplifications were performed in a PCR express (Thermohybaid) thermocycler with the following parameters; denaturation for $30 \mathrm{~s}$ at $98^{\circ} \mathrm{C}$, followed by 35 cycles of $10 \mathrm{~s}$ at $98^{\circ} \mathrm{C}, 30 \mathrm{~s}$ at the specific hybridization temperature, and $45 \mathrm{~s}$ at $72^{\circ} \mathrm{C}$ for polymerization. A final extension step of $10 \mathrm{~min}$ at $72^{\circ} \mathrm{C}$ was included.

Both strands were sequenced in an automatic sequencer (Applied Biosystem 3130 A, Perkin Elmer, Coignières, France) with primers using the Big Dye Terminator Kit version 3.1 (Applied Biosystems, Coignières, France). DNA sequence analysis was carried out using SeqScape software 2.5 (Applied Biosystems, Coignières, France). Nucleotide alignments were determined using the programs ClustalW (http://www.ebi.ac.uk/clustalw/) and BLAST (http://www.ncbi.nlm.nih.gov, last accessed in November 2007).

\subsection{Trans-complementation of the naturally occurring S. Heidelberg hypermutator strain}

The wild-type mutS gene was amplified by PCR using mutS-SacI and SphI primers (Table 2). The PCR product was digested with the restriction endonucleases SacI and SphI and ligated into the pGEMT vector (Promega, Charbonières, France). The vector was transformed into competent cells of $S$. Heidelberg hypermutator $(\mathrm{Hm})$ by heat shock as 
previously described (Sambrook et al., 1982). Transformed cells were selectively plated on Tryptic Soy (AES Laboratory, Combourg, France) plates with ampicillin $(100 \mu \mathrm{g} / \mathrm{mL}$, Sigma Aldrich, Saint Quentin Fallavier, France).

\section{5. $3 D$ representation}

S. Typhimurium LT2 and E. coli MutS proteins have a high sequence homology (http://www.ncbi.nlm.nih.gov/blast/Blast.cgi), which led us to compare their 3D structures. The 3D structure of the Salmonella Muts protein was compared to an in silico 3D representation of MutS E.coli structure (Genbank accession number n $\left.{ }^{\circ} 1 \mathrm{OH} 5\right)$ (Natrajan et al., 2003), generated using Cn3D software (http://www.ncbi.nlm.nih.gov/Structure). This 3D structure was used to analyze the structure of the Salmonella MutS protein.

\subsection{DNA binding assay}

Binding of both wild-type and mutated MutS proteins to DNA was assessed using a gel retardation assay. Proteins from both $S$. Heidelberg wild-type and a hypermutator of the same serovar were expressed in a His 6 -tagged vector and extracted and purified using the QIAexpression kit (Qiagen, Courtaboeuf, France), as described below.

To make the His-tagged expression construct, mutS DNA from each strain was amplified by PCR using the primers mutS-SacI-prot and mutS-SphI (Table 2). A dATP was added to the 3 ' terminus using Taq polymerase enzyme (Promega, Charbonières, France) in a second and final extension step. Each PCR product was ligated into the pQE-30-UA (ampicillin resistant) vector (QIAexpression kit, Qiagen, Courtaboeuf, France). Recombinant plasmids were transformed into E. coli M15 pREP4 (kanamycin resistant) according to the manufacturer's instructions. The orientation of the cloned mutS gene was verified by 
digestion with $S a c \mathrm{I}$ and $A s c \mathrm{I}$. In the correct orientation, the mutS gene is under the control of PT5 promoter.

His $_{6}$-tagged MutS proteins were expressed in E. coli cultures incubated overnight in LB broth supplemented with ampicillin $(100 \mu \mathrm{g} / \mathrm{mL})$ and kanamycin $(20 \mu \mathrm{g} / \mathrm{mL})$. Proteins from each strain were extracted (under denaturing conditions), eluted, and purified (under native conditions), according to the QIAexpression kit recommendations. Proteins were purified with a Ni-NTA matrix (Ni-Sepharose 6 Fast-Flow, GE Healthcare, Orsay, France). Protein extracts were mixed with the Ni-NTA matrix for $1 \mathrm{~h}$ and then loaded onto a column, proteins were washed with buffer $\left(50 \mathrm{mM} \mathrm{NaH}_{2} \mathrm{PO}_{4}, 300 \mathrm{mM} \mathrm{NaCl}, 20 \mathrm{mM}\right.$ imidazole, $\mathrm{pH}$ 7.4) (Sigma Aldrich, Saint Quentin Fallavier, France). Then proteins were eluted in 3 fractions with elution buffer $\left(50 \mathrm{mM} \mathrm{NaH} \mathrm{PO}_{4}, 300 \mathrm{mM} \mathrm{NaCl}, 250 \mathrm{mM}\right.$ imidazole, $\mathrm{pH}$ 7.4) (Sigma Aldrich, Saint Quentin Fallavier, France). Total protein concentration was measured using the 2D quant kit (GE Healthcare, Orsay, France).

DNA from $S$. Heidelberg wild type (wt) and a hypermutator phenotype (Hm) was amplified with primers RrlA1, RrlA2, and RrlAbis (Table 2). The 259 bp PCR products (rrla1-rrla2 and rrlabis-rrla2) were identical, except for a single nucleotide at position 9 (T-C substitution). PCR products were purified using Qiagen columns (Qiagen, Courtaboeuf, France). To prepare heteroduplex DNA, the two DNA fragments were mixed as described by Stanislawska-Sachadyn et al. (2003). The mixture of the two PCR products contained both homoduplex and heteroduplex DNA fragments (Stanislawska-Sachadyn et al., 2003).

The DNA gel retardation assay was performed using 6 and $8 \mu \mathrm{g}$ of purified $\mathrm{His}_{6}$ tagged MutS proteins (wt and $\mathrm{Hm}$ ). The DNA-MutS complexes were prepared as described previously (Stanislawska-Sachadyn et al., 2003). Two controls were used, one with only DNA and one with DNA complexed with BSA (6 $\mu \mathrm{g}$ ) (purity 98\%, Sigma Aldrich, Saint Quentin Fallavier, France). Each sample was electrophoresed in a 2\% TAE agarose gel at 5 
$\mathrm{mA} / \mathrm{cm}$ in a $2 \%$ TAE agarose gel, at room temperature for $14 \mathrm{~h}$. Protein-DNA complexes were visualized by staining with ethidium bromide.

\subsection{Statistical analysis}

Statistical analysis was assessed using 2-sample student's tests or the Wilcoxon 2-sample test using $\mathrm{t}$ approximation, where appropriate. Categorical variables were assessed using $\chi^{2}$ tests exact test. A $p$ value $<0.05$ was considered to be statistically significant.

\section{Results}

\subsection{Phenotypic identification}

No phenotypic differences in identification profiles were observed between $S$. Heidelberg Hm (B182) and wt using the API 20E gallery. Some differences were found using API 32GN; $S$. Heidelberg Hm, in contrast to wt, was not able to grow in the presence of Lalanine, L-serine, lactic acid and propionic acid.

\subsection{Mutation rates of Salmonella strains}

The distribution of rifampicin mutation frequencies of 209 Salmonella isolates from veterinary and human origin was determined, using phenotypic categories previously established by Baquero et al. (2004): hypomutable $\left(f \leq 8 \times 10^{-9}\right)$, normomutable $\left(8 \times 10^{-9}<f\right.$ $<4 \times 10^{-8}$ ), weakly hypermutable $\left(4 \times 10^{-8} \leq f<4 \times 10^{-7}\right)$, and strongly hypermutable $(f \geq 4 \times$

$10^{-7}$ ) (Figure 1). A significantly higher proportion of hypomutable strains were isolated from humans $(38.7 \%)$ than from animals $(18.4 \%, p=0.001)$. Among human clinical isolates, only $3.3 \%$ were weakly hypermutable compared with strains from animal origin $(15.6 \%, p=0.011)$. Only the B182 bovine strain of $S$. Heidelberg (Hm) (one strain/209, incidence $0.7 \%$ ) showed a high frequency of mutation using rifampicin, fosfomycin, or nalidixic acid. According to 
the criterion described by Leclerc et al. (1996), this strain was categorized as a strong hypermutable isolate. Its frequency of mutation to rifampicin resistance was greater than 50 fold higher $\left(395 \pm 100\right.$ per $\left.10^{8} \mathrm{CFU} / \mathrm{mL}\right)$ than a wild-type strain (wt) of the same serovar $(4 \pm$ 2.5 per $10^{8} \mathrm{CFU} / \mathrm{mL}$ ) (Table 3). Its frequency of mutation was also 50 fold higher than the other Salmonella strains (median value 2.7 per $10^{8} \mathrm{CFU} / \mathrm{mL}$ ).

\subsection{MMR gene sequences of the S. Heidelberg hypermutator strain}

Sequencing showed no evidence that the MutL, MutH, Dam, and UvrD (CP001120.1) proteins were mutated in the $S$. Heidelberg hypermutable strain B182. Sequences were identical to previous sequenced genes of Salmonella Heidelberg SL 476. Mutations observed in the mutL gene (Genbank Accession number FJ39011) were silent mutations.

The $m u t$ S gene of the S.Heidelberg B182 (Genbank Accession number FJ539012) was sequenced and analyzed using available databases. A 12 bp deletion in position 1075 to 1086 was identified. In order to determine if the $12 \mathrm{bp}$ deletion might be present in other Salmonella serovars and if this deletion constitutes a genetic polymorphism, the sequences of mutS genes from several Salmonella enterica strains were compared using available databases. Sequence alignments of the $m u t S$ gene from the genome of S.Typhimurium LT2 showed a nearly identical match to all strains of the serovars Salmonella: S.Heidelberg wt (100\%), S. Cholerasuis, S.Paratyphi A, S.Typhi CT18, and S. Typhi Ty2 (99\%). In contrast, alignment with the $S$.Heidelberg hypermutator, confirmed the $12 \mathrm{bp}$ deletion was only present in this strain (Figure 2).

The nucleotides in this 12 bp sequence encode amino acids LRTA (359-362) (Figure 2), and there were no other modifications in the open reading frame (ORF). The hypothetical location of the LRTA motif on the 3D protein structure of MutS was determined using 
http://www.ncbi.nlm.nih.gov/Structure/CN3D/cn3d.shtml. The 3D structure was modeled from the E. coli MutS protein (E24377A or O157:H7 strain Sakai), which has 95\% homology with MutS from Salmonella Typhimurium LT2. This analysis revealed the LRTA motif might form a link between 2 beta-sheets in the core domain.

To investigate if the $12 \mathrm{bp}$ deletion could be restored, the $S$. Heidelberg hypermutator strain was trans-complemented with the mutS wild-type gene from wt S.Heidelberg. The resulting trans-complemented hypermutator strain showed a decrease $(\sim 1 \log )$ in the frequency of mutation when exposed to rifampicin, fosfomycin, and nalidixic acid (Table 3). Thus, the wild-type phenotype was partially restored.

\subsection{DNA gel retardation assay}

The purified proteins MutS Hm and MutS wt were tested in a DNA gel retardation assay for their ability to anchor homoduplex or heteroduplex DNA (with or without a mismatch). The migration of DNA (homoduplexes or heteroduplexes) in the absence of protein on the gel was faster than the migration of DNA in the presence of MutS wt (Figure 3). Therefore, MutS wt protein was able to anchor the DNA (with or without mismatch). Similar results were also obtained for MutS Hm (Figure 3). No binding was observed when DNA was mixed with BSA. Thus, the mutS-12 bp deletion does not appear to inhibit MutS from anchoring DNA.

\section{Discussion}

This work describes the first isolation of a S.Heidelberg with a hypermutator phenotype. Hypermutation allows some bacterial cells to adapt to adverse environmental conditions, including antibiotic exposure (Blazquez, 2003; Chopra et al., 2003; Woodford and Ellington, 
2007). Stressful conditions, changing environment, or extreme nutrient limitation are known to place bacteria at risk. Bacteria respond through a mutational alteration of genotype (Sundin et al. 2007).

The criteria for distinguishing mutators from non-mutators have been arbitrarily determined by some authors. Besier et al. (2008) demonstrated that thymidine-dependent small-colony variant phenotype was associated with hypermutability in $S$. aureus, but no study was able to show significant phenotypic difference linked to the hypermutator phenotype. Tompkins et al. (2003) determined $\sim 0.1 \%$ of $E$ coli bacterial cells are hypermutators (with a mutation rate up to 200-fold higher than normal). They also found only $10 \%$ of the adaptive Lac + mutations arise in hypermutators. Leclerc et al. (1996) stated cells exhibiting an increase in mutation frequencies of just 50-fold or more should be considered mutators. Accordingly, they reported a higher incidence of mutators, with an average of $3.6 \%$ among isolates of Salmonella enterica and $1.9 \%$ among E. coli isolates. Significant variations have been observed in mutation frequencies between clinical isolates from different origins and ecotypes (Baquero et al., 2004; Denamur et al., 2002). Denamur et al. (2002) showed uropathogenic E. coli strains had a higher frequency of mutators than enterohemorragic and enteroinvasive strains.

Only a few studies are available on the subject of mutation rates of strains isolated from fecal samples. Baquero et al (2004) previously established phenotypic categories, studying a collection of 300 E. coli isolates from Spain, and found $69 \%$ of fecal strains from healthy volunteers were normo-mutagenic, whereas $11 \%$ were weakly mutagenic. They found a higher proportion of hypomutagenic strains (19\%) from healthy volunteers than from those with bacteremia or urinary tract infection. The implication of hypermutation in virulence remains conflicting; some authors attesting increasing virulence (Bayliss et al 2008), while others showed hypermutation reduced virulence due to biological cost (Merino 
et al. 2002; Montarini et al. 2007). No difference in susceptibility to antimicrobial agents (both quite susceptible, data not shown) was observed between the wild type and hypermutator strain, in agreement Denamur et al (2002) who demonstrated uropathogenic Escherichia coli mutator strains were not more resistant than non-mutators. Data on resistance to antimicrobial agents remains controversial in literature (Komp Lingren et al 2003, Baquero et al 2005).

Most mutator strains have mutations in the methyl-directed mismatch repair genes. In the presence of both ATP and a mismatch, MutS recruits MutL. Together they activate MutH and initiate the entire MMR system. The binding of MutS to DNA is very important for successful DNA repair. MutS recognizes errors, such as mismatches, with varying efficiencies (Parker and Marinus, 1992). The crystalline structure of the MutS-DNA complex from E. coli has proven very important in understanding the nature of protein-DNA interactions (Mendillo et al., 2007). A mutation in the mutS gene causes a hypermutable phenotype (LeClerc et al., 1996; Matic et al., 2006). Leclerc et al. (1996) examined a natural Escherichia coli $\mathrm{O} 157: \mathrm{H} 7$ strain and found a $200 \mathrm{bp}$ deletion at the 3' end of the mutS gene, which conferred a mutator phenotype. Additionally, they examined five strains of natural populations of Salmonella enterica and found three out of five carried a mutS mutation. The other two strains had mutations in $m u t H$ and $u v r D$. In this work, a 12-bp deletion (AA358$362,1075-1087 \mathrm{bp}$ ) was identified in the $m u t S$ gene of $S$. Heidelberg. A complementation assay indicated the wt $m u t \mathrm{~S}$ gene only partially restored repair activity in the $m u t \mathrm{~S}$ deficient S.Heidelberg Hm. This could indicate a partial activity of MutS Hm or a mutation or dysregulation of regulatory gene(s). DNA mismatch repair is an evolutionarily conserved process that corrects mismatch errors that escape proofreading during DNA replication. Defects in this system usually result in a hypermutable phenotype (Leclerc et al 1996; Matic et al. 2006). DNA repair is initiated upon recognition of a mismatch by MutS. MutS, which 
binds to insertion-deletion-loops (IDL's) that are 1- 4 nucleotides in length, also binds to 7 and 8 bp mismatches (Hsieh, 2001; Wang et al., 2003).

The 3D structure of E. coli MutS revealed 6 functional domains. From 5' to 3', they are: (1) the mismatch binding site (aa 1 to aa 115), (2) the connector (aa 116 to aa 257), (3) the core domain (aa 266 to aa 443), (4) the lever clamp domain (aa 444 to aa 567), (5) the ATPase domain (aa 568 to aa 765), and (6) the helix-turn-helix (dimer contact) in the Cterminal domain (aa 766 to stop) (Marti et al., 2002). Mutational studies have identified some functions of these domains. Calmann et al. (2005) showed deletion of 53 amino acids from the C-terminus of MutS resulted in (1) an increased mutation rate of about 60-fold and (2) a MutS-protein with a lower affinity than MutS for certain oligonucleotides with base pair mismatches, that in the presence of other MMR components reduced the efficiency of MutHinduced incision at hemimethylated GATC sequences in vitro. Miguel et al. (2007) showed the K850A substitution destabilized the tetramer structure which is the active form of MutS. The authors proposed the C-terminal extreme alpha helix (aa 839-850) might play an important role in protein oligomerization. Mendillo et al. (2007) demonstrated dimerization, but not tetramerization, of the MutS C terminus is essential for mismatch repair. Two models have been proposed in E. coli to explain the initiation of the mismatch repair system: (1) cis model: movement of the MutS or MutS-[MutL and/or other proteins] complex along the helix between the mismatch and the d(GATC)-strand signal and (2) trans model: the two sites interact in a DNA-looping mechanism (Kolodner et al., 2007). Assembly of the MutS-MutL heteroduplex complex is sufficient to activate both MutH endonuclease and DNA helicase II. A conformational change in MutS dimers directs recruitment of MutL dimers and might allow the formation of two channels that can receive DNA. The mutS $12 \mathrm{bp}$ deletion appeared to have no influence on the ability of the protein to anchor or bind DNA. It is hypothesized the $12 \mathrm{bp}$ deletion in the core domain of MutS may either prevent binding to MutL or modify the 
conformation of the MutS dimer. In support of this idea, Joseph et al. (2005) suggested conformational changes in Haemophilus influenzae MutS modulate mismatch recognition and trigger some of downstream repair processes. Crystallization of the Salmonella MutS protein would reveal if MutS-MutL interactions are present.

Bacterial mismatch repair (MMR) deficient mutants, exhibiting high mutation and homologous recombination rates, are frequently found in natural populations. These high mutation rates are expected to favor their environmental adaptation. The $12 \mathrm{bp}$ deletion in the mutS gene of the S.Heidelberg $\mathrm{Hm}$ was only partially responsible for the hypermutator phenotype observed and has no influence on anchorage of the MutS protein on DNA. Mechanisms other than the MMR system might be involved in hypermutation. A better understanding of the genetic mechanisms and regulatory schemes of hypermutation will help anticipate behavior of hypermutatable strains in mixed bacterial populations and their role in survival ability.

\section{Acknowledgments}

This work was supported by the Conseil Regional d'Ille et Vilaine (Scholarship) and Fondation Langlois. We thank AM Gouraud and A Bodin for their technical assistance and Sylvie Bataillon for statistical analysis. We also thank the Veterinary Laboratory of Ille et Vilaine and the Laboratory of Medical Bacteriology (CHU Pontchaillou, Rennes) for the collection of Salmonella strains. We thank Ouest Genopole and the Teaching Hospital (CHU Rennes) for their technical supports.

\section{Conflict of interest statement}

All authors disclose there are no financial and personal relationships with other people or organizations that could inappropriately influence their work. 


\section{References}

Vaillant V., de Valk H., Baron E., Ancelle T., Colin P., Delmas M.C., Dufour B., Pouillot R., Le Strat Y., Weinbreck P., Jougla E., Desenclos J.C. 2005. Foodborne infections in France. Foodborne Pathog. Dis. 2, 221-232.

Zhao S., White D.G., Friedman S.L., Glenn A., Blickenstaff K., Ayers S.L., Abbott J.W., Hall-Robinson E., McDermott P.F. 2008. Antimicrobial resistance in Salmonella enterica serovar Heidelberg from Retail Meat and Poultry, 2002-2006. Appl. Environ. Microbiol. 74, 6656-6662.

LeClerc J.E., Li B., Payne W.L., Cebula T.A. 1996. High mutation frequencies among Escherichia coli and Salmonella pathogens. Science 274, 1208-1211.

Merino D., Reglier-Poupet H., Berche P., Charbit A. 2002. A hypermutator phenotype attenuates the virulence of Listeria monocytogenes in a mouse model. Mol. Microbiol. $44,877-887$.

Matic I., Radman M., Taddei F., Picard B., Doit C., Bingen E., Denamur E., Elion J. 1997. Highly variable mutation rates in commensal and pathogenic Escherichia coli. Science $277,1833-1834$.

Taddei F., Radman M., Maynard-Smith J., Toupance B., Gouyon P.H., Godelle B. 1997. Role of mutator alleles in adaptive evolution. Nature 387, 700-702.

Boe L., Danielsen M., Knudsen S., Petersen J.B., Maymann J., Jensen P.R. 2000. The frequency of mutators in populations of Escherichia coli. Mutat. Res. 448, 47-55.

Chopra I., O'Neill A.J., Miller K. 2003. The role of mutators in the emergence of antibioticresistant bacteria. Drug Resist Updat 6, 137-145. 
Matic I., Ekiert D., Radman M., Kohiyama M. 2006. Generation of DNA-free Escherichia coli cells by 2-aminopurine requires mismatch repair and nonmethylated DNA. J. Bacteriol. 188, 339-342.

Yang W. 2000. Structure and function of mismatch repair proteins. Mutat. Res. 460, 245-256.

Radman M., Matic I., Halliday J.A., Taddei F. 1995. Editing DNA replication and recombination by mismatch repair: from bacterial genetics to mechanisms of predisposition to cancer in humans. Philos. Trans. R. Soc. Lond., B, Biol. Sci. 347, 97103.

Oliver A., Canton R., Campo P., Baquero F., Blazquez J. 2000. High frequency of hypermutable Pseudomonas aeruginosa in cystic fibrosis lung infection. Science 288, 1251-1254.

Prunier A.L., Malbruny B., Laurans M., Brouard J., Duhamel J.F., Leclercq R., 2003. High rate of macrolide resistance in Staphylococcus aureus strains from patients with cystic fibrosis reveals high proportions of hypermutable strains. J. Infect. Dis. 187, 17091716.

Denamur E., Bonacorsi S., Giraud A., Duriez P., Hilali F., Amorin C., Bingen E., Andremont A., Picard B., Taddei F., Matic I. 2002. High frequency of mutator strains among human uropathogenic Escherichia coli isolates. J. Bacteriol. 184, 605-609.

Sambrook J., Fritsch E.F., Maniatis T. 1982. Molecular cloning: A laboratory manual, Second Edition Cold Spring Harbor, New York.

Natrajan G., Lamers M.H., Enzlin J.H., Winterwerp H.H., Perrakis A., Sixma T.K. 2003. Structures of Escherichia coli DNA mismatch repair enzyme MutS in complex with different mismatches: a common recognition mode for diverse substrates. Nucleic Acids Res. 31, 4814-4821. 
Stanislawska-Sachadyn A., Sachadyn P., Jedrzejczak R., Kur J. 2003. Construction and purification of his6-Thermus thermophilus MutS protein. Protein Expr. Purif. 28, 6977.

Baquero M.R., Nilsson A.I., Turrientes Mdel C., Sandvang D., Galan J.C., Martinez J.L., Frimodt-Moller N., Baquero F., Andersson D.I.. 2004. Polymorphic mutation frequencies in Escherichia coli: emergence of weak mutators in clinical isolates. J. Bacteriol. 186, 5538-5542.

Blazquez J. 2003. Hypermutation as a factor contributing to the acquisition of antimicrobial resistance. Clin. Infect. Dis. 37, 1201-1209.

Woodford N., Ellington M.J. 2007. The emergence of antibiotic resistance by mutation. Clin. Microbiol. Infect. 13, 5-18.

Sundin G.W., Weigand M.R..2007. The microbiology of mutability FEMS Microbiol Lett. 277:11-20.

Besier S., Zander J., Kahl B.C., Kraiczy P., Brade V., Wichelhaus T.A. 2008. The thymidinedependent small colony-variant phenotype is associated with hypermutability and antibiotic resistance in clinical Staphylococcus aureus isolates. Antimicrob. Agents Chemother. 52, 2183-2189.

Tompkins J.D., Nelson J.L., Hazel J.C., Leugers S.L., Stumpf J.D., Foster P.L. 2003. Errorprone polymerase, DNA polymerase IV, is responsible for transient hypermutation during adaptive mutation in Escherichia coli. J. Bacteriol. 185, 3469-3472.

Bayliss C.D., Hoe J.C., Makepeace K., Martin P., Hood D.W., Moxon, E.R. 2008. Neisseria meningitidis escape from the bactericidal activity of a monoclonal antibody is mediated by phase variation of lgtG and enhanced by a mutator phenotype. Infect Immun. 76, 5038-5048. 
Montanari S., Oliver A., Salerno P., Mena A., Bertoni G., Tümmler B., Cariani L., Conese M., Döring G., Bragonzi A. 2007. Biological cost of hypermutation in Pseudomonas aeruginosa strains from patients with cystic fibrosis. Microbiology. 153,:1445-1454.

Komp Lindgren P., Marcusson L.L., Sandvang D., Frimodt-Moller N., Hughes D. 2005. Biological cost of single and multiple norfloxacin resistance mutations in Escherichia coli implicated in urinary tract infections. Antimicrob Agents Chemother. 49, 23432351.

Baquero M.R., Galan J.C., del Carmen Turrientes M., Canton R., Coque T.M., Martinez J.L., Baquero F. 2005. Increased mutation frequencies in Escherichia coli isolates harboring extended-spectrum beta-lactamases. Antimicrob Agents Chemother. 49, 4754-4756.

Parker B.O., Marinus M.G. 1992. Repair of DNA heteroduplexes containing small heterologous sequences in Escherichia coli. Proc. Natl. Acad. Sci. U.S.A. 89, 17301734.

Mendillo M.L., Putnam C.D., Kolodner R.D. 2007. Escherichia coli MutS tetramerization domain structure reveals that stable dimers but not tetramers are essential for DNA mismatch repair in vivo. J. Biol. Chem. 282, 16345-16354.

Hsieh P. 2001. Molecular mechanisms of DNA mismatch repair. Mutat. Res. 486, 71-87.

Wang H., Yang Y., Schofield M.J., Du C., Fridman Y., Lee S.D., Larson E.D., Drummond J.T., Alani E., Hsieh P., Erie D.A. 2003. DNA bending and unbending by MutS govern mismatch recognition and specificity. Proc. Natl. Acad. Sci. U.S.A. 100, $14822-14827$.

Marti T.M., Kunz C., Fleck O. 2002. DNA mismatch repair and mutation avoidance pathways. J. Cell. Physiol. 191, 28-41. 
Calmann M.A., Nowosielsk, A., Marinus M.G. 2005. The MutS C terminus is essential for mismatch repair activity in vivo. J. Bacteriol. 187, 6577-6579.

Miguel V., Pezza R.J., Argarana C.E. 2007. The C-terminal region of Escherichia coli MutS and protein oligomerization. Biochem. Biophys. Res. Commun. 360, 412-417.

Kolodner R.D., Mendillo M.L., Putnam C.D. 2007. Coupling distant sites in DNA during DNA mismatch repair. Proc. Natl. Acad. Sci. U.S.A. 104, 12953-12954.

Joseph N., Duppatla V., Rao D.N. 2005. Functional characterization of the DNA mismatch binding protein MutS from Haemophilus influenzae. Biochem. Biophys. Res. Commun. 334, 891-900. 
Table 1 Distribution of different serovars of Salmonella enterica isolates studied

\section{Sources of the strains}

Salmonella enterica serovars

Number of isolates

\begin{tabular}{llllll}
\hline Human & Cattle & Sheep & Pig & Poultry & Total
\end{tabular}

S. Typhimurium

17

58

1

18

7

101

S. Montevideo

1

32

0

0

0

33

S. Enteritidis

15

2

1

0

0

18

S. Hadar

7

0

0

0

0

7

$S$. Derby

1

2

0

4

0

7

S. Virchow

5

0

0

0

0

5

S. Heidelberg

3

2

0

0

0

5

Other

13

16

1

3

0

33

Total

62

112

3

25

7

209 
Table 2 Primers used in this study ${ }^{a}$

\begin{tabular}{|c|c|}
\hline Primers used for sequencing & Sequences $5^{\prime} \rightarrow 3^{\prime}$ \\
\hline mutLA & TAT ATA CCG GGG GTT GCG TA \\
\hline mutLB & TAA ATG AGG GCG GAA TCA AC \\
\hline mutL1 & AGTAAAATCGCCTCGCTTGA \\
\hline mutL2 & GTTTCTCGAACAGGCACTGG \\
\hline mutL3 & GCCCTGCTTCTGATAAC \\
\hline mutL7 & CAAATTCATGCGTACCGAAA \\
\hline mutL8 & CTTTTAAACGCAGCGGAATC \\
\hline mutSlong1 & GAGCATGGTCTGAACTAATTGC \\
\hline mutSlong2 & CCCTTATTTACGCTGTCTGTCT \\
\hline mutS1 & CCCCTGTTGTAGTCCAGGAA \\
\hline mutS2 & GGCTATCTGGCAGGATGGTA \\
\hline mutS3 & GGCCAGGTTCTGGGTAATTT \\
\hline mutS4 & AAGTCGGCTATAACGCGGTA \\
\hline mutS5 & CGGGTAAAAATACGGTCGAT \\
\hline mutS6 & CGACAGTCACAGCCTGAAAA \\
\hline mutS7 & CCAATATGGGCGGTAAAAGT \\
\hline mutS8 & GGTAGCCGAATGCTTAAACG \\
\hline mutS9 & TTTGACCACGGCTAATCTGA \\
\hline mutS10 & GAATTACACCTGCCCGACAT \\
\hline mutS11 & GCTGTTTTATGACGACGACGCAA \\
\hline mutS12 & CGCCGTCGCCCGTTGTGGGA \\
\hline mutS13 & TGCTTGACTGTACCGTGACGCC \\
\hline mutS14 & ACGGCGATACTATCGCGTTTAT \\
\hline mut $\mathrm{H} 1$ & AGAATTGGAAAACCCGCTTC \\
\hline mut $\mathrm{H} 4$ & TGCAAGACTTCGCCATGA \\
\hline dam 1 & CTGCAATTGCCTGTGAGTGT \\
\hline dam4 & CGTACTGACGCAGGGATTTC \\
\hline$u v r D A$ & GTTTACTGCCGCATATCGAA \\
\hline$u v r D \mathrm{~B}$ & CGAAACGCGAAAAAGCAATA \\
\hline uvrD2 & AGCGAAGATCAGATGCGTTT \\
\hline uvrD3 & GAGCAGAATTACCGCTCGAC \\
\hline$u v r D 4$ & GCACACCTGCCACAATGTTA \\
\hline uvrD5 & CTGCATGGCACGGGTAAC \\
\hline $\begin{array}{c}\text { Primers used for trans } \\
\text { complementation experiment }\end{array}$ & Sequences $5^{\prime} \rightarrow 3^{\prime}$ \\
\hline mutS-SacI & GTAAAGAGCTCATGAATGAGTCATTTGATA \\
\hline mutS-SphI & TCTGGCATGCTTACACCAGACTTTTCAG \\
\hline $\begin{array}{c}\text { Primers used for DNA binding } \\
\text { assay }\end{array}$ & Sequences $5^{\prime} \rightarrow 3^{\prime}$ \\
\hline rrlA1 & TTCTAACGTGGACCCGTAAT \\
\hline rrlA2 & GTTATCCCCGGAGTACCTTT \\
\hline rrlA bis & TTCTAACGCGGACCCGTAAT \\
\hline mutS-Sac1-prot & AGTAAAGAGCTCATGAATGAGTCATTTGAT \\
\hline
\end{tabular}

\footnotetext{
${ }^{a}$ Restriction sites are underlined.
} 
Table 3 Mutation rates of the different S.Heidelberg used in this study (selection on rifampicin $100 \mu \mathrm{g} / \mathrm{ml})$.

\section{Number of mutator strains per $10^{8} \mathrm{CFU} / \mathrm{mL}$}

\begin{tabular}{lccc}
\cline { 2 - 3 } Salmonella Heidelberg & Rifampicin & Nalidixic acid & Fosfomycin \\
strains & $100 \mu \mathrm{g} / \mathrm{mL}$ & $50 \mu \mathrm{g} / \mathrm{mL}$ & $100 \mu \mathrm{g} / \mathrm{mL}$ \\
\hline Wild-type (wt) & $4 \pm 2.5$ & 0 & $28 \pm 6.5$ \\
\hline B182 hypermutator (Hm) & $395 \pm 100$ & $236 \pm 60$ & $12360 \pm 1310$ \\
mutS wild-type trans & $65 \pm 20$ & $30 \pm 15$ & $1568 \pm 650$ \\
complemented hypermutator & & & \\
& & & \\
\hline
\end{tabular}




\section{Figure legends}

Figure 1: Distribution of rifampicin mutation frequencies $(f)$ of 209 Salmonella isolates from veterinary (dark) and human (white) sources. Categories: hypomutable (hypo) $\left(f \leq 8 \times 10^{-9}\right)$, normomutable (normo) $\left(8 \times 10^{-9}<f<4 \times 10^{-8}\right)$, weakly hypermutable (weak) $\left(4 \times 10^{-8} \leq f<\right.$ $\left.4 \times 10^{-7}\right)$, and strongly hypermutable (strong) $\left(f \geq 4 \times 10^{-7}\right)$.

Figure 2: Partial sequence alignment of the mutS gene and MutS protein of four Salmonella strains: S.Typhimurium LT2 (GenBank NC0031971), S.Heidelberg wt, SL476 (GenBank CP001120), and S.Heidelberg Hm (B182) (GenBank FJ539011). Deleted nucleic acids and amino acid are shown in bold.

Figure 3: The DNA gel retardation assay. $20 \mu \mathrm{L}$ of each sample (His ${ }_{6}$-tagged $S$. Heidelberg MutS wt or $\mathrm{Hm}$ ) was loaded on a $2 \%$ gel. Their ability to anchor to homodimer and heterodimer DNA was tested (in lanes 2 to 5). Their ability to anchor to only homodimer DNA was tested (in lanes 7 to 10). The DNA molecular weight marker is in lane 11. Lanes 1 and 6 show the DNA migration in the absence of added MutS protein. MW: Molecular weight marker VIII (Roche, Meylan, France).

\section{Figure 1}




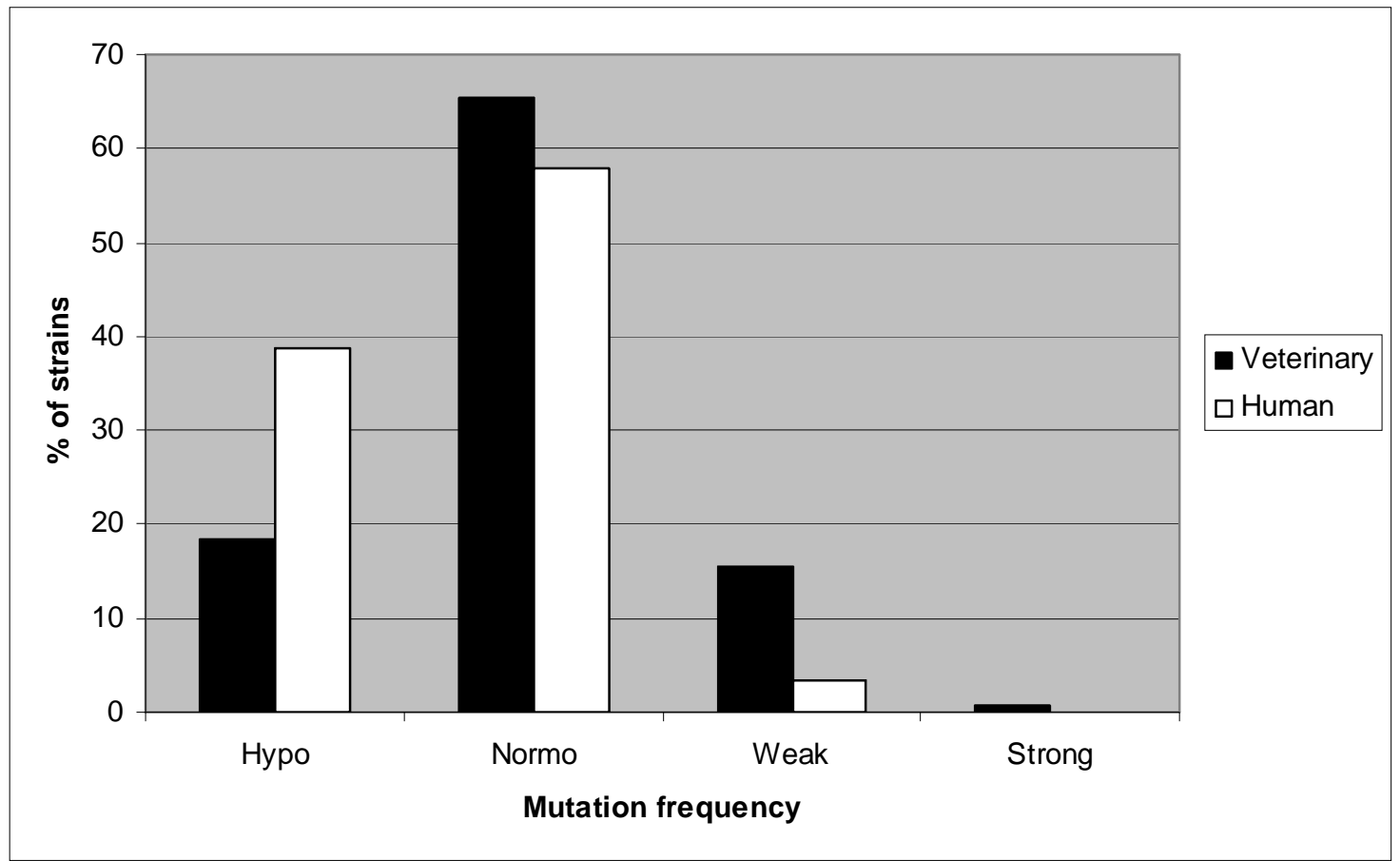


Figure 2

\begin{tabular}{|c|c|c|c|}
\hline S.Typhimurium LT2 & GCG & CTG CGC ACC GCG CGT & $\mathrm{CCG}$ \\
\hline & A & 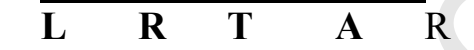 & $\mathrm{P}$ \\
\hline S.Heidelberg wt & $\mathrm{GCG}$ & CTG CGC ACC GCG CGT & $\mathrm{CCG}$ \\
\hline & A & $\begin{array}{lllll}\mathbf{L} & \mathbf{R} & \mathbf{T} & \mathbf{A} & \mathrm{R}\end{array}$ & $\mathrm{P}$ \\
\hline S.Heidelberg SL476 & GCG & CTG CGC ACC GCG CGT & $\mathrm{CCG}$ \\
\hline & A & $\begin{array}{lllll}\mathbf{L} & \mathbf{R} & \mathbf{T} & \mathbf{A} & \mathrm{R}\end{array}$ & $\mathrm{P}$ \\
\hline S.Heidelberg Hm (B182) & $\begin{array}{c}\text { GCG } \\
\text { A }\end{array}$ & C-------- & $\begin{array}{c}\mathrm{CCG} \\
\mathrm{P}\end{array}$ \\
\hline
\end{tabular}


1

2

3

5

Sałmonella Heidelberg strain

9

Hits $s_{6}$ MutS quantity ( $\left.\mu \mathrm{g}\right)$

13

BSA $(\mu \mathrm{g})$

15

D̄XA Homodimer

19

Heterodimer

3

5
Figure 3.

21

23

25

27

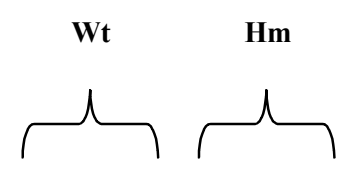

$\begin{array}{llllll}0 & 6 & 8 & 6 & 8\end{array}$

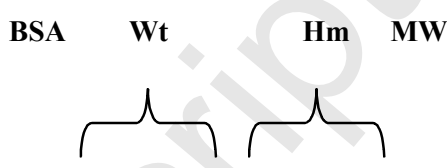

$\begin{array}{lllllll}0 & 6 & 8 & 6 & 8\end{array}$

$\begin{array}{llllll}6 & 0 & 0 & 0 & 0\end{array}$

$\begin{array}{llllll}\mathbf{0} & \mathbf{0} & \mathbf{0} & \mathbf{0} & \mathbf{0}\end{array}$

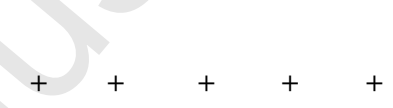

$+\quad+\quad+\quad+$

$+\quad+\quad+\quad+\quad+$

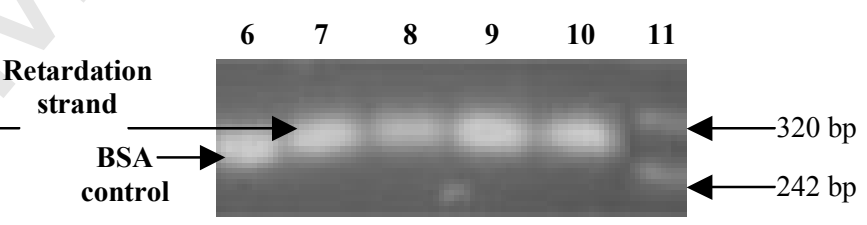

28

29

30 